\title{
Ratings of The Investment Projects of Arbitrary Durations: New Methodology
}

\author{
P.N. Brusov ${ }^{1, *}$, T.V. Filatova ${ }^{2}$, N.P. Orekhova ${ }^{3}$, V.L. Kulik ${ }^{4}$ and I. Weil ${ }^{5}$ \\ ${ }^{1}$ Department of Data Analysis, Decision Making, and Financial Technology, Financial University under the \\ Government of Russian Federation, Moscow, Russia \\ ${ }^{2}$ Department of Corporate Finance and Corporate Governance, Financial University under the Government of \\ Russian Federation. Moscow, Russia \\ ${ }^{3}$ High Business school, Southern Federal University, Rostov-on-Don. Russia \\ ${ }^{4}$ Department of Management, Financial University under the Government of Russian Federation. Moscow, \\ Russia \\ ${ }^{5}$ Northwestern University, Evanston, USA
}

\begin{abstract}
In this paper we develop for the first time a new approach to ratings of the investment projects of arbitrary durations, which could be applied to investments of any area of economy and in particular to energy projects. The ratings of such energy projects, as "Turkish stream", "Nord stream-2", energy projects relating to clean, renewable and sustainable energy, as well as relating to pricing carbon emissions (McAleer et al., 2018a,b,c; 2019) could be done using developed here new rating methodologies. In our previous papers the new approach to the ratings of the long-term investment projects has been developed (Filatova et al., 2018). The important features of that consideration are as following: 1) The incorporation of rating parameters (financial "ratios"), used in project rating and playing a major role in it, into modern long-term investment models, 2) The adequate use of discounting of financial flows virtually not used in existing project rating methodologies. Here, for the first time, we incorporate the rating parameters (financial "ratios"), used in project rating, into modern investment models, describing the investment projects of arbitrary durations. This was much more difficult task then in case of the long-term investment projects, considered by us in previous papers. We work within investment models, created by authors. One of them describes the effectiveness of investment project from perspective of equity capital owners, while other model describes the effectiveness of investment project from perspective of equity capital and debt capital owners. New approach allows use the powerful instruments of modern theory of capital cost and capital structure (BFO theory) (Brusov et al., 2015, 2018) and modern investment models, created by the authors and well tested in the real economy to evaluate investment project performance, including energy projects.

In our calculations we use Excel technique in two aspects: 1) we calculate WACC at different values of equity costs $\mathrm{k}_{0}$, different values of debt costs $k_{d}$ and different values of leverage level $L=D / S$, using the famous BFO formula; 2) we calculate the dependences of NPV on coverage ratios as well as leverage ratios at different values of equity costs $k_{0}$, different values of debt costs $\mathrm{k}_{\mathrm{d}}$ and different values of leverage level $L$.
\end{abstract}

Keywords: Arbitrary duration investment projects, rating, rating methodology, discounting of financial flows, Brusov-Filatova-Orekhova theory, coverage ratios, leverage ratios.

\section{INTRODUCTION}

The investments play a very important role in economics and finance. Wherein the role of energy projects in general and in particular relating to clean, renewable and sustainable energy, as well as relating to pricing carbon emissions rapidly increasing.

In the conditions of limited financial resources, the selection of the most efficient projects from the point of view of investors becomes a very important task. Rating agencies are called upon to solve it.

*Address correspondence to these authors at the Department of Data Analysis, Decision Making, and Financial Technology, Financial University under the Government of Russian Federation. Moscow, Russia; Tel: +7(906)0675975; Fax:+7(906)0675975; E-mail: pnb1983@yahoo.com

JEL Classification: C53, L94, Q47.
Rating agencies play a very important role in economics. Their analysis of issuer's state, generated credit ratings of issuers, of investment projects help investors make reasonable investment decision, as well as help issuer with good enough ratings get credits on lower rates etc.

But the methodologies of leading rating agencies, such as "The Big Three credit rating agencies" (Standard \& Poor's (S\&P), Moody's, and Fitch Group) as well as Russian rating agency ACRA and all other ones have a lot of shortcomings. A number of works by authors are devoted to eliminating some of these shortcomings (Brusov et al., 2018, 2018a, 2018b, 2018c, 2018d).

Besides the fact, that RA represent some "black boxes", the information about the methods of work of 
which is almost completely absent, there are some serious methodological and systematic errors in their activity. These errors and ways to their overcome have been discussed in a number of authors papers (Brusov et al., 2018, 2018a,b,c,d), as well as in monograph (Brusov et al., 2018).

\section{The Use of Discounting in the Rating}

One of the major flaws of all existing rating methodologies is a failure or a very narrow use of discounting. But even in those rare cases where it is used, it is not quite correct, since the discount rate when discounting financial flows is chosen incorrectly.

As (Brusov et al., 2018) have mentioned "The need to take into account the time factor in terms of discounting is obvious, because it is associated with the time value of money. The financial part of the rating is based on a comparison of generated income with the value of the debt and the interest payable. Because income and disbursement of debt and interest are separated in time, the use of discounting when comparing revenues with the value of debt and interest is absolutely necessary for assigning credit ratings for issuers".

This raises the question about the value of discount rate. This question has always been one of the major and extremely difficult in many areas of Finance: corporate finance, investment, it is particularly important in business valuation, where a slight change in the discount rate leads to a significant change in the assessment of company capitalization, that is used by unscrupulous appraisers for artificial bankruptcy of the company. It is extremely essential as well in rating.

\section{Incorporation of Financial "Ratios", Using in Ratings, into Modern Investment Models}

In quantification of the creditworthiness of the issuers as well as in valuation of effectiveness of investment projects the crucial role belongs to the socalled financial "ratios", constitute a direct and inverse ratios of various generated cash flows to debt values and interest ones. We incorporate these financial "ratios", into the modern theory of capital structure Brusov-Filatova-Orekhova (BFO) theory (Brusov et al. 2018) and as well into modern investment models, created by the authors.

Such incorporation, which has been done by us for the first time, is very important because one can use this theory as a powerful tools when discounting of financial flows using the correct discounting rate in rating. Only this theory allow valuate adequately the weighted average cost of capital WACC and equity cost ke used when discounting of financial flows.

As Brusov et al. 2018 have mentioned "Use of the tools of well developed theories in rating opens completely new horizons in the rating industry, which could be connected with transition from the mainly use of qualitative methods of the evaluation of the creditworthiness of issuers to a predominantly quantitative evaluation methods that will certainly enhance the quality and correctness of the rating".

Currently, RA just directly use financial ratios, while the new methodology will allow (knowing the values of these "relations" (and parameter k0)) determine the correct values of discount rates (WACC and ke) that should be used when discounting the various financial flows, both in terms of their timing as well as forecasting.

In relation to the rating of investment projects new methodology allows correctly determine the values of project NPV (both in units of $D$ as well as in NOI), using modern investment models and correct discount rate.

As Brusov et al. 2018 mentioned "Incorporation of financial "ratios", has required the modification of the BFO theory (and its perpetuity limit - so called Modigliani - Miller theory), as used in financial management the concept of "leverage" as the ratio of debt value to the equity value substantially differs from the concept of "leverage" in the rating, where it is understood as the direct and inverse ratio of the debt value to the generated cash flow values (income, revenue etc.). The authors introduced some additional ratios, allowing more fully characterize the issuer's ability to repay debts and to pay interest thereon".

Thus the bridge is building between the discount rates (WACC, $\mathrm{k}_{\mathrm{e}}$ ) used when discounting of financial flows, and "ratios" in the rating methodology.

The important features of current consideration as well as in previous studies are: 1) The adequate use of discounting of financial flows virtually not used in existing rating methodologies, 2) The incorporation of rating parameters (financial "ratios"), used in project rating, into considered modern investment models.

\section{INVESTMENT MODELS}

We work within investment models, created by authors. One of them describes the effectiveness of investment project from perspective of equity capital 
owners, while other model describes the effectiveness of investment project from perspective of equity capital and debt capital owners.

In the former case, investments at the initial time moment $T=0$ are equal to $-S$ and the flow of capital for the period (in addition to the tax shields $k_{\mathrm{d}} D t$ it includes a payment of interest on a loan $-k_{\mathrm{d}} D$ ):

$C F=\left(\right.$ NOI $\left.-k_{\mathrm{d}} D\right)(1-t)$.

Here, for simplicity, we suppose that interest on the loan will be paid in equal shares $k_{\mathrm{d}} D$ during all periods. Note that principal repayment is made at the end of the last period.

We will consider the case of discounting, when operating and financial flows are not separated and both are discounted, using the general rate (as which, obviously, the weighted average cost of capital (WACC) can be selected). In case for long-term (perpetuity) projects, the Modigliani-Miller formula (Modigliani and Miller 1958, 1963, 1966) for WACC has been used (Brusov et al., 2018) and for projects of finite (arbitrary) duration Brusov-Filatova-Orekhova formula will be used (Brusov and Filatova 2011; Brusov et al. 2011a, b, c, 2012a, b, 2013a, b. 2014a, b; Filatova et al. 2008; Brusova 2011).

Note that debt capital is the least risky, because interest on credit is paid after taxes in the first place. Therefore, the cost of credit will always be less than the equity cost, whether of ordinary or of preference shares $k_{\mathrm{e}}>k_{\mathrm{d}} ; k_{\mathrm{p}}>k_{\mathrm{d}}$. Here $k_{\mathrm{e}}, k_{\mathrm{p}}$ is the equity cost of ordinary or of preference shares consequently.

2.1. The Effectiveness of the Investment Project from the Perspective of the Equity Holders Only (Without Flows Separation)

In this case operating and financial flows are not separated and are discounted. using the general rate (as which, obviously, WACC can be selected).

The credit reimbursable at the end of the project (at the end of the period $(n)$ ) can be discounted either at the same rate WACC or at the debt cost rate $k_{\mathrm{d}}$. Now we choose a uniform rate and the first option.

$$
\begin{aligned}
\mathrm{NPV}= & -S+\sum_{i=1}^{n} \frac{\mathrm{NOI}(1-t)-k_{\mathrm{d}} D(1-t)}{(1+\mathrm{WACC})^{i}}-\frac{D}{(1+\mathrm{WACC})^{n}} \\
= & -S+\frac{\mathrm{NOI}(1-t)-k_{\mathrm{d}} D(1-t)}{\mathrm{WACC}} \\
& \left(1-\frac{1}{(1+\mathrm{WACC})^{n}}\right)-\frac{D}{(1+\mathrm{WACC})^{n}} .
\end{aligned}
$$

At a Constant Value of Equity Capital ( $S=$ const $)$

Accounting that in the case $S=$ const $\mathrm{NOI}$ is proportional to the invested capital, $I$, $\mathrm{NOI}=\beta I=\beta S(1+L)$ and substituting $D=L S$, we get

$$
\begin{aligned}
& \mathrm{NPV}=-S+\frac{\mathrm{NOI}(1-t)-k_{\mathrm{d}} D(1-t)}{\mathrm{WACC}} \\
& \quad\left(1-\frac{1}{(1+\mathrm{WACC})^{n}}\right)-\frac{D}{(1+\mathrm{WACC})^{n}}, \\
& \mathrm{NPV}=-S\left[1+\frac{L k_{\mathrm{d}}(1-t)}{\mathrm{WACC}}\left(1-\frac{1}{(1+\mathrm{WACC})^{n}}\right)+\frac{L}{(1+\mathrm{WACC})^{n}}\right] \\
& +\frac{\beta S(1+L)(1-t)}{\mathrm{WACC}}\left(1-\frac{1}{(1+\mathrm{WACC})^{n}}\right) . \\
& N P V=-S\left[1+\frac{k_{d} L(1-t)}{W A C C}\left(1-\frac{1}{(1+W A C C)^{n}}\right)+\frac{L}{(1+W A C C)^{n}}\right] \\
& +\frac{\beta S(1+L)(1-t)}{W A C C}\left(1-\frac{1}{(1+W A C C)^{n}}\right) .
\end{aligned}
$$

\section{INCORPORATION OF FINANCIAL COEFFICIENTS, USING IN PROJECT RATING, INTO MODERN INVESTMENT MODELS, DESCRIBING THE INVESTMENT PROJECTS OF ARBITRARY DURATION}

Below for the first time we incorporate the financial coefficients, used in project rating, into modern investment models, describing the investment projects of arbitrary duration, created by authors. We will consider two kind of financial coefficients: coverage ratios as well as leverage coefficients. In each group of financial coefficients we incorporate three particular quantities.

For coverage ratios we incorporate: 1) coverage ratios of debt, $\left.i_{1}=\frac{N P V}{D} ; 2\right)$ coverage ratios of interest on the credit $\left.i_{2}=\frac{N P V}{k_{d} D} ; 3\right)$ coverage ratios of debt and interest on the credit $i_{3}=\frac{N P V}{\left(1+k_{d}\right) D}$.

For leverage ratios we incorporate: 1) leverage ratios of debt, $l_{1}=\frac{D}{N P V} ; 2$ ) leverage ratios of interest on the credit $\left.l_{2}=\frac{k_{d} D}{N P V} ; 3\right)$ leverage ratios of debt and interest on the credit $l_{3}=\frac{\left(1+k_{d}\right) D}{N P V}$. 


\subsection{Coverage Ratios}

\subsubsection{Coverage Ratios of Debt}

Let us first incorporate the coverage ratios, using in project rating, into modern investment models, describing the investment projects of arbitrary duration, created by authors. Dividing both parts of equation (5) by $D$ one gets

$$
\begin{aligned}
\frac{N P V}{D}= & -\frac{1}{L}+\frac{\left(i_{1}-k_{d}\right)(1-t)}{W A C C}\left(1-\frac{1}{(1+W A C C)^{n}}\right) \\
& -\frac{1}{(1+W A C C)^{n}}
\end{aligned}
$$

Here $i_{1}=\frac{N P V}{D}$

\subsubsection{Coverage Ratios of Interest on the Credit}

Dividing both parts of equation (5) by $k_{\mathrm{d}} D$ one gets

$$
\begin{aligned}
\frac{N P V}{k_{d} D}= & -\frac{1}{k_{d} L}+\frac{\left(i_{2}-k_{d}\right)(1-t)}{W A C C}\left(1-\frac{1}{(1+W A C C)^{n}}\right) \\
& -\frac{1}{k_{d}(1+W A C C)^{n}}
\end{aligned}
$$

Here $i_{2}=\frac{N P V}{k_{d} D}$

\subsubsection{Coverage Ratios of Debt and Interest on the Credit}

Dividing both parts of equation (5) by $\left(1+k_{\mathrm{d}}\right) D$ one gets

$\frac{N P V}{\left(1+k_{d}\right) D}=\frac{1}{\left(1+k_{d}\right)}\left[-\frac{1}{L}+\frac{\left(\left(1+k_{d}\right) i_{3}-k_{d}\right)(1-t)}{W A C C}\left(1-\frac{1}{(1+W A C C)^{n}}\right)-\frac{1}{(1+W A C C)^{n}}\right]$

Here $i_{3}=\frac{N P V}{\left(1+k_{d}\right) D}$

\subsection{Leverage Ratios}

\subsubsection{Leverage Ratios for Debt}

Now let us incorporate the leverage ratios, using in project rating, into modern investment models, created by authors.

Dividing both parts of equation (5) by $\mathrm{NO}$ one gets

$$
\begin{aligned}
\frac{N P V}{N O I}= & -\frac{l_{1}}{L}+\frac{\left(1-k_{d} l_{1}\right)(1-t)}{W A C C}\left(1-\frac{1}{(1+W A C C)^{n}}\right) \\
& -\frac{l_{1}}{(1+W A C C)^{n}}
\end{aligned}
$$

Here $l_{1}=\frac{D}{N P V}$

\subsubsection{Leverage Ratios for Interest on Credit}

$$
\begin{aligned}
\frac{N P V}{N O I} & =-\frac{l_{2}}{k_{d} L}+\frac{\left(1-l_{2}\right)(1-t)}{W A C C}\left(1-\frac{1}{(1+W A C C)^{n}}\right) \\
& -\frac{l_{2}}{k_{d}(1+W A C C)^{n}}
\end{aligned}
$$

Here $l_{2}=\frac{k_{d} D}{N P V}$

\subsubsection{Leverage Ratios for Debt and Interest on Credit}

$$
\frac{N P V}{N O I}=\frac{1}{1+k_{d}}\left[-\frac{l_{3}}{L}+\frac{\left(1+k_{d}-k_{d} l_{3}\right)(1-t)}{W A C C}\left(1-\frac{1}{(1+W A C C)^{n}}\right)-\frac{l_{3}}{(1+W A C C)^{n}}\right]
$$

Here $l_{3}=\frac{\left(1+k_{d}\right) D}{N P V}$.

Let us investigate below the effectiveness of investment projects of arbitrary duration studying the dependence of NPV on coverage ratios and on leverage ratios. We make calculations for coefficients $i_{1}$ and $l_{1}$. Calculations for the rest of coefficients $\left(i_{2}, i_{3}\right.$ and $I_{2}, l_{3}$ ) could be made in a similar way.

We start from the calculations of the dependence of NPV on coverage ratios. We consider different values of equity costs $k_{0}$, different values of debt costs $k_{d}$ and different values of leverage level $L=D / S$. Here $t$ is tax on profit rate, which in our calculations is equal to $20 \%$.

\section{RESULTS AND ANALYSIS}

\subsection{Dependence of NPV/D on Coverage Ratios}

Below we calculate the dependence of NPV (in units of $\mathrm{D})\left(\frac{N P V}{D}\right)$ on coverage ratio on debt $i_{1}$ at different equity costs $k_{0}$ ( $k_{0}$ is the equity cost at zero leverage level $\mathrm{L}=0$ ). We will make calculations for two leverage levels $L(L=1$ and $L=3)$, for two project 
durations $(n=2$ and $n=5)$ and for different credit rates $\mathrm{k}_{\mathrm{d}}$. In our calculations we use Excel technique in two aspects: 1) we calculate WACC at different values of equity costs $k_{0}$, different values of debt costs $k_{d}$ and different values of leverage level $L=D / S$, using the famous BFO formula; 2) we calculate the dependences of NPV on coverage ratios as well as leverage ratios at different values of equity costs $k_{0}$, different values of debt costs $k_{d}$ and different values of leverage level $L$. We use typical values of equity costs $k_{0}$, of debt costs $\mathrm{k}_{\mathrm{d}}$ and of leverage level $L$.

For calculation of the dependence of NPV/D on coverage ratio on debt $i_{1}$ within BFO approximation (arbitrary duration projects) we use the formula (6)

$$
\begin{aligned}
\frac{N P V}{D} & =-\frac{1}{L}+\frac{\left(i_{1}-k_{d}\right)(1-t)}{W A C C}\left(1-\frac{1}{(1+W A C C)^{n}}\right) . \\
& -\frac{1}{(1+W A C C)^{n}}
\end{aligned}
$$

\subsubsection{The Dependence of NPV on Coverage Ratio on Debt $i_{1}$}

Below we investigate the dependence of NPV/D on coverage ratio on debt $i_{1}$ at different values of equity costs $k_{0}$, at different values of debt costs $k_{d}$ at fixed value of equity cost, as well as at different values of leverage levels $L$.

Let us start our calculations from the case of equity cost $\mathrm{k}_{0}=14 \%$.

1. We calculate WACC, using the famous BFO formula (Brusov et al., 2015, 2018)

$\frac{1-(1+W A C C)^{-n}}{W A C C}=\frac{1-\left(1+k_{o}\right)^{-n}}{k_{o} *\left[1-W d * t *\left(1-\left(1+k_{d}\right)^{-n}\right)\right]}$.

Here $k_{0}$ is equity costs, $k_{d}$ is debt costs; $L=D / S$ is the leverage level; $t$ is tax on profit rate, $w_{d}$ is debt ratio, WACC is weighted average capital cost, $n$ is the project duration.

2. We calculate dependence of NPV/D (NPV in units $\mathrm{D}$ ) on coverage ratio on debt $i_{1}$, using obtained value of WACC, which depends on $\mathrm{k}_{0}$, $\mathrm{k}_{\mathrm{d}}, \mathrm{t}, \mathrm{n}, \mathrm{L}$.

3. We calculate NPV/NOI (NPV in units NOI) on leverage ratio on debt $l_{1}$, using obtained value of WACC, which depends on $k_{0}, k_{d}, t, n, L$.

The results are shown in Tables and Figures.
Table 1: The Dependence of NPV/D on Coverage Ratio on Debt $i_{1}$ at $\mathrm{L}=1, \mathrm{k}_{0}=14 \% ; \mathrm{k}_{\mathrm{d}}=12 \% ; \mathrm{t}=20 \%, \mathrm{n}=2$

\begin{tabular}{|c|c|c|c|}
\hline $\mathbf{i}_{1}$ & $\mathbf{n}$ & NPV/D & WACC \\
\hline \hline 0 & 2 & -1.86035 & 0.185838 \\
\hline 1 & 2 & -0.61682 & 0.185838 \\
\hline 2 & 2 & 0.626711 & 0.185838 \\
\hline 3 & 2 & 1.870243 & 0.185838 \\
\hline 4 & 2 & 3.113776 & 0.185838 \\
\hline 5 & 2 & 4.357308 & 0.185838 \\
\hline 6 & 2 & 5.600841 & 0.185838 \\
\hline 7 & 2 & 6.844373 & 0.185838 \\
\hline 8 & 2 & 8.087906 & 0.185838 \\
\hline 9 & 2 & 9.331438 & 0.185838 \\
\hline 10 & 2 & 10.57497 & 0.185838 \\
\hline
\end{tabular}

Table 2: The Dependence of NPV/D on Coverage Ratio on Debt $i_{1}$ at $\mathrm{L}=1, \mathrm{k}_{0}=14 \% ; \mathrm{k}_{\mathrm{d}}=12 \% ; \mathrm{t}=20 \%, \mathrm{n}=5$

\begin{tabular}{|c|c|c|c|}
\hline $\mathbf{i 1}$ & $\mathbf{n}$ & NPV/D & WACC \\
\hline \hline 0 & 5 & -2.0942 & 0.072849 \\
\hline 1 & 5 & 1.161083 & 0.072849 \\
\hline 2 & 5 & 4.41637 & 0.072849 \\
\hline 3 & 5 & 7.671658 & 0.072849 \\
\hline 4 & 5 & 10.92694 & 0.072849 \\
\hline 5 & 5 & 14.18223 & 0.072849 \\
\hline 6 & 5 & 17.43752 & 0.072849 \\
\hline 7 & 5 & 20.69281 & 0.072849 \\
\hline 8 & 5 & 23.94809 & 0.072849 \\
\hline 9 & 5 & 27.20338 & 0.072849 \\
\hline 10 & 5 & 30.45867 & 0.072849 \\
\hline
\end{tabular}

Table 3: The Dependence of NPV/D on Coverage Ratio on Debt $i_{1}$ at $L=3, k_{0}=14 \% ; k_{d}=12 \% ; t=20 \%, n=2$

\begin{tabular}{|c|c|c|c|}
\hline $\mathbf{i 1}$ & $\mathbf{n}$ & NPV/D & WACC \\
\hline \hline 0 & 2 & -1.19238 & 0.186786 \\
\hline 1 & 2 & 0.049707 & 0.186786 \\
\hline 2 & 2 & 1.291792 & 0.186786 \\
\hline 3 & 2 & 2.533877 & 0.186786 \\
\hline 4 & 2 & 3.775963 & 0.186786 \\
\hline 5 & 2 & 5.018048 & 0.186786 \\
\hline 6 & 2 & 6.260133 & 0.186786 \\
\hline 7 & 2 & 7.502218 & 0.186786 \\
\hline 8 & 2 & 8.744303 & 0.186786 \\
\hline 9 & 2 & 9.986389 & 0.186786 \\
\hline 10 & 2 & 11.22847 & 0.186786 \\
\hline
\end{tabular}


Table 4: The Dependence of NPV/D on Coverage Ratio on Debt $i_{1}$ at $L=3, k_{0}=14 \% ; k_{d}=12 \% ; t=20 \%, n=5$

\begin{tabular}{|c|c|c|c|c|}
\hline $\mathbf{L}$ & $\mathbf{i}_{1}$ & $\mathbf{n}$ & NPV/D & WACC \\
\hline \hline 3 & 0 & 5 & -1.42302 & 0.073898 \\
\hline 3 & 1 & 5 & 1.823185 & 0.073898 \\
\hline 3 & 2 & 5 & 5.069387 & 0.073898 \\
\hline 3 & 3 & 5 & 8.315588 & 0.073898 \\
\hline 3 & 4 & 5 & 11.56179 & 0.073898 \\
\hline 3 & 5 & 5 & 14.80799 & 0.073898 \\
\hline 3 & 6 & 5 & 18.05419 & 0.073898 \\
\hline 3 & 7 & 5 & 21.30039 & 0.073898 \\
\hline 3 & 8 & 5 & 24.5466 & 0.073898 \\
\hline 3 & 9 & 5 & 27.7928 & 0.073898 \\
\hline 3 & 10 & 5 & 31.039 & 0.073898 \\
\hline
\end{tabular}

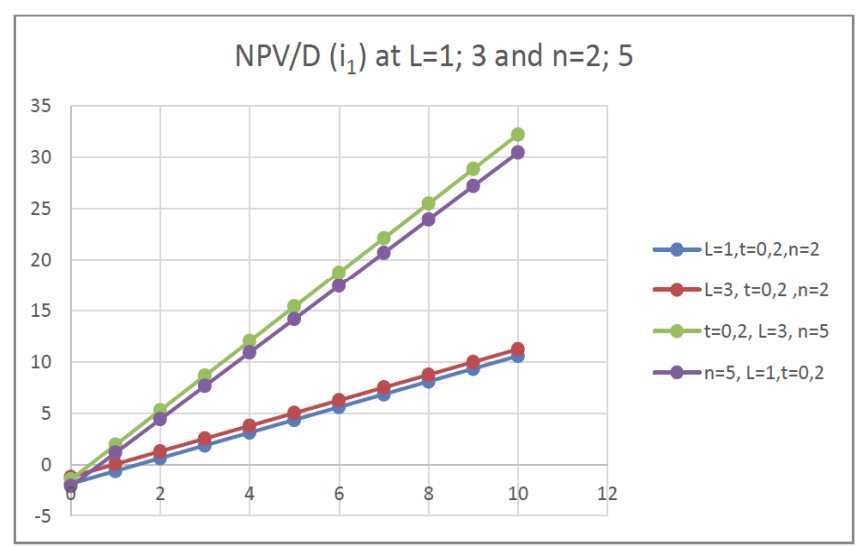

Figure 1: The dependence of NPV/D on coverage ratio on debt $i_{1}$ at $\mathrm{L}=1$ and $3, \mathrm{k}_{0}=14 \% ; \mathrm{k}_{\mathrm{d}}=12 \% ; \mathrm{t}=20 \%, \mathrm{n}=2 ; 5$.

We see from the Tables 1-4 and from Figure 1, that NPV (in units of D) $\left(\frac{N P V}{D}\right)$ increases with $\mathrm{i}_{1}$.

The features of this increase are as following:

1) the angle $\mathrm{NPV}\left(\mathrm{i}_{1}\right)$ is determined by the project duration $\mathrm{n}$ : it increases with $\mathrm{n}$.

2) with increase of leverage level $L$ the curve $\mathrm{NPV}\left(\mathrm{i}_{1}\right)$ shifts practically parallel up. Thus, NPV increases with debt financing.

This means, that influence of the project duration $n$ on the dependence of NPV/D on coverage ratio on debt $i_{1}$ is more significant, than influence of leverage level $\mathrm{L}$.

\subsubsection{The Dependence of NPV on Leverage Ratio on Debt $l_{1}$}

We see from the Tables 5-8 and from Figure 2, that NPV (in units of NOI) $\left(\frac{N P V}{N O I}\right)$ decreases with $\mathrm{l}_{1}$.

Table 5: The Dependence of NPV/NOI on Leverage Ratio on Debt $I_{1}$ at $L=1, k_{0}=14 \% ; k_{d}=12 \% ; t=20 \%, n=2$

\begin{tabular}{|c|c|c|c|}
\hline $\mathbf{L}$ & $\mathbf{n}$ & WACC & NPV/NOI \\
\hline \hline 1 & 2 & 0.1231 & 1.346553406 \\
\hline 1 & 2 & 0.1231 & -0.6078321 \\
\hline 1 & 2 & 0.1231 & -2.5622176 \\
\hline 1 & 2 & 0.1231 & -4.5166031 \\
\hline 1 & 2 & 0.1231 & -6.47098861 \\
\hline 1 & 2 & 0.1231 & -8.42537411 \\
\hline 1 & 2 & 0.1231 & -10.3797596 \\
\hline 1 & 2 & 0.1231 & -12.3341451 \\
\hline 1 & 2 & 0.1231 & -14.2885306 \\
\hline 1 & 2 & 0.1231 & -16.2429161 \\
\hline 1 & 2 & 0.1231 & -18.1973016 \\
\hline
\end{tabular}

Table 6: The Dependence of NPV/NOI on Leverage Ratio on Debt $l_{1}$ at $L=3, k_{0}=14 \% ; k_{d}=12 \% ; t=20 \%, n=2$

\begin{tabular}{|c|c|c|c|c|}
\hline $\mathbf{L}$ & $\mathbf{I}_{\mathbf{1}}$ & $\mathbf{n}$ & WACC & NPV/NOI \\
\hline \hline 3 & 0 & 2 & 0.13203 & 1.330967788 \\
\hline 3 & 1 & 2 & 0.13203 & 0.057577565 \\
\hline 3 & 2 & 2 & 0.13203 & -1.21581266 \\
\hline 3 & 3 & 2 & 0.13203 & -2.48920288 \\
\hline 3 & 4 & 2 & 0.13203 & -3.7625931 \\
\hline 3 & 5 & 2 & 0.13203 & -5.03598332 \\
\hline 3 & 6 & 2 & 0.13203 & -6.30937355 \\
\hline 3 & 7 & 2 & 0.13203 & -7.58276377 \\
\hline 3 & 8 & 2 & 0.13203 & -8.85615399 \\
\hline 3 & 9 & 2 & 0.13203 & -10.1295442 \\
\hline 3 & 10 & 2 & 0.13203 & -11.4029344 \\
\hline
\end{tabular}

The features of this decrease are as following:

1) the angle $\operatorname{NPV}\left(I_{1}\right)$ is determined by the leverage level $L$ : it increases with $L$. Thus, NPV increases with debt financing.

2) with increase of project duration $n$ the curve $\mathrm{NPV}\left(\mathrm{I}_{1}\right)$ shifts practically parallel up. 
Table 7: The Dependence of NPV/NOI on Leverage Ratio on Debt $I_{1}$ at $L=1, k_{0}=14 \% ; k_{d}=12 \% ; t=20 \%, n=5$

\begin{tabular}{|c|c|c|c|c|}
\hline $\mathbf{L}$ & $\mathbf{l}_{\mathbf{1}}$ & $\mathbf{n}$ & WACC & NPV/NOI \\
\hline \hline 1 & 0 & 5 & 0.121819 & 2.870871 \\
\hline 1 & 1 & 5 & 0.121819 & 0.963526 \\
\hline 1 & 2 & 5 & 0.121819 & -0.94382 \\
\hline 1 & 3 & 5 & 0.121819 & -2.85116 \\
\hline 1 & 4 & 5 & 0.121819 & -4.75851 \\
\hline 1 & 5 & 5 & 0.121819 & -6.66585 \\
\hline 1 & 6 & 5 & 0.121819 & -8.5732 \\
\hline 1 & 7 & 5 & 0.121819 & -10.4805 \\
\hline 1 & 8 & 5 & 0.121819 & -12.3879 \\
\hline 1 & 9 & 5 & 0.121819 & -14.2952 \\
\hline 1 & 10 & 5 & 0.121819 & -16.2026 \\
\hline
\end{tabular}

Table 8: The Dependence of NPV/NOI on Leverage Ratio on Debt $I_{1}$ at $L=3, k_{0}=14 \% ; k_{d}=12 \% ; t=20 \%, n=5$

\begin{tabular}{|c|c|c|c|c|}
\hline $\mathbf{L}$ & $\mathbf{I}_{\mathbf{1}}$ & $\mathbf{n}$ & WACC & NPV/NOI \\
\hline \hline 3 & 0 & 5 & 0.130962 & 2.807196 \\
\hline 3 & 1 & 5 & 0.130962 & 1.596542 \\
\hline 3 & 2 & 5 & 0.130962 & 0.385889 \\
\hline 3 & 3 & 5 & 0.130962 & -0.82476 \\
\hline 3 & 4 & 5 & 0.130962 & -2.03542 \\
\hline 3 & 5 & 5 & 0.130962 & -3.24607 \\
\hline 3 & 6 & 5 & 0.130962 & -4.45672 \\
\hline 3 & 7 & 5 & 0.130962 & -5.66738 \\
\hline 3 & 8 & 5 & 0.130962 & -6.87803 \\
\hline 3 & 9 & 5 & 0.130962 & -8.08868 \\
\hline 3 & 10 & 5 & 0.130962 & -9.29934 \\
\hline
\end{tabular}

This means, that influence of leverage level $L$ on the dependence of NPV/NOI on leverage ratio on debt $l_{1}$ is more significant, than influence of the project duration $\mathrm{n}$.

One can see that the dependence of NPV/NOI on leverage ratio on debt $I_{1}$ is opposite to the dependence of NPV/D on coverage ratio on debt $i_{1}$ :

1) the angle $\operatorname{NPV}\left(I_{1}\right)$ is determined by the leverage level $\mathrm{L}$, while the angle $\operatorname{NPV}\left(\mathrm{i}_{1}\right)$ is determined by the project duration $n$.

2) with increase of project duration $n$ the curve $\mathrm{NPV}\left(\mathrm{I}_{1}\right)$ shifts practically parallel up, while such kind of behavior is typical for influence of the leverage level $L$ in case of the curve NPV $\left(i_{1}\right)$.

The only one common thing for both curves $\operatorname{NPV}\left(I_{1}\right)$ and $\mathrm{NPV}\left(\mathrm{i}_{1}\right)$ is that NPV increases with debt financing (or with the leverage level $L$ ).

\subsubsection{The Dependence of NPV on Coverage Ratio on Debt $i_{1}$ at Different Values of $k_{d}$}

Let us investigate the dependence of NPV/D on coverage ratio on debt $i_{1}$ at $\mathrm{L}=3, \mathrm{k}_{0}=20 \% ; \mathrm{k}_{\mathrm{d}}=18 \%$; $\mathrm{t}=20 \%, \mathrm{n}=2$.

The straight lines for different $k_{d}$ turn out practically merge, which means that the influence of the variation of $k_{d}$ on such a scale of changes $i_{1}$ is insignificant. In order to evaluate the ordering of straight lines corresponding to different $k_{d}$, we increase the scale in the following figures, considering the values of $i_{1}$ not from 0 to 10 , but from 0 to 1 . In Figure 4 , we consider the case of different project duration $\mathrm{n}$, while in Figure 5 the case of different leverage level $\mathrm{L}$.

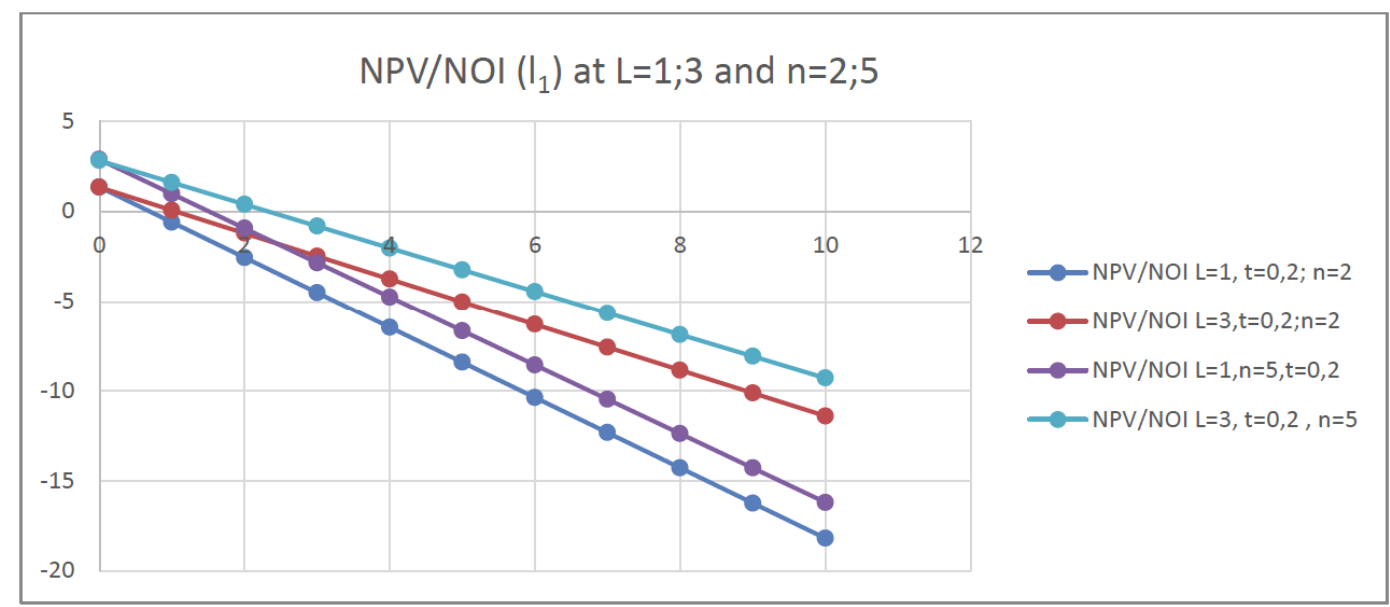

Figure 2: The dependence of NPV/NOI on leverage ratio on debt $l_{1}$ at $L=1 ; 3, k_{0}=14 \% ; k_{d}=12 \% ; t=20 \%, n=2 ; 5$. 
Table 9: The Dependence of NPV/D on Coverage Ratio on Debt $i_{1}$ at $L=3, k_{0}=20 \% ; k_{d}=18 \% ; t=20 \%, n=2$

\begin{tabular}{|c|c|c|c|c|}
\hline $\mathbf{L}$ & $\mathbf{n}$ & $\mathbf{i}_{\mathbf{1}}$ & NPV/D & WACC \\
\hline \hline 3 & 2 & 0 & -1.281958725 & 0.176679108 \\
\hline 3 & 2 & 1 & -0.024284066 & 0.176679108 \\
\hline 3 & 2 & 2 & 1.233390593 & 0.176679108 \\
\hline 3 & 2 & 3 & 2.491065253 & 0.176679108 \\
\hline 3 & 2 & 4 & 3.748739912 & 0.176679108 \\
\hline 3 & 2 & 5 & 5.006414571 & 0.176679108 \\
\hline 3 & 2 & 6 & 6.264089231 & 0.176679108 \\
\hline 3 & 2 & 7 & 7.52176389 & 0.176679108 \\
\hline 3 & 2 & 8 & 8.779438549 & 0.176679108 \\
\hline 3 & 2 & 9 & 10.03711321 & 0.176679108 \\
\hline 3 & 2 & 10 & 11.29478787 & 0.176679108 \\
\hline
\end{tabular}

Table 10: The Dependence of NPV/D on Coverage Ratio on Debt $i_{1}$ at $\mathrm{L}=3, \mathrm{k}_{0}=20 \% ; \mathrm{k}_{\mathrm{d}}=16 \% ; \mathrm{t}=20 \%, \mathrm{n}=2$.

\begin{tabular}{|c|c|c|c|c|}
\hline $\mathbf{n}$ & $\mathbf{L}$ & $\mathbf{i}_{1}$ & WACC & NPV/D \\
\hline \hline 2 & 3 & 0 & 0.18198583 & -1.249017883 \\
\hline 2 & 3 & 1 & 0.18198583 & 0.000427777 \\
\hline 2 & 3 & 2 & 0.18198583 & 1.249873438 \\
\hline 2 & 3 & 3 & 0.18198583 & 2.499319098 \\
\hline 2 & 3 & 4 & 0.18198583 & 3.748764758 \\
\hline 2 & 3 & 5 & 0.18198583 & 4.998210418 \\
\hline 2 & 3 & 6 & 0.18198583 & 6.247656078 \\
\hline 2 & 3 & 7 & 0.18198583 & 7.497101739 \\
\hline 2 & 3 & 8 & 0.18198583 & 8.746547399 \\
\hline 2 & 3 & 9 & 0.18198583 & 9.995993059 \\
\hline 2 & 3 & 10 & 0.18198583 & 11.24543872 \\
\hline
\end{tabular}

Table 11: The Dependence of NPV/D on Coverage Ratio on Debt $i_{1}$ at $L=3, k_{0}=20 \% ; k_{d}=14 \% ; t=20 \%, n=2$.

\begin{tabular}{|c|c|c|c|c|}
\hline $\mathbf{n}$ & $\mathbf{L}$ & $\mathbf{i}_{1}$ & WACC & NPV/D \\
\hline \hline 2 & 3 & 0 & 0.183805688 & -1.221437995 \\
\hline 2 & 3 & 1 & 0.183805688 & 0.025207969 \\
\hline 2 & 3 & 2 & 0.183805688 & 1.271853932 \\
\hline 2 & 3 & 3 & 0.183805688 & 2.518499896 \\
\hline 2 & 3 & 4 & 0.183805688 & 3.76514586 \\
\hline 2 & 3 & 5 & 0.183805688 & 5.011791823 \\
\hline 2 & 3 & 6 & 0,183805688 & 6.258437787 \\
\hline 2 & 3 & 7 & 0,183805688 & 7.505083751 \\
\hline 2 & 3 & 8 & 0,183805688 & 8.751729714 \\
\hline 2 & 3 & 9 & 0,183805688 & 9.998375678 \\
\hline 2 & 3 & 10 & 0,183805688 & 11.24502164 \\
\hline
\end{tabular}

One can see from Figure 5, that the ordering of the NPV/D straight lines for different credit rates $k_{d}$ and different leverage level $L$ turns out to be as following: two triplets, corresponding to different leverage level $\mathrm{L}$ are well distinguished and upper triplet (with bigger NPV value) corresponds to bigger leverage level $L=3$.

This means that NPV increases with debt financing. Within each triplet NPV decreases with credit rates kd: the biggest NPV corresponds to $k_{d}=14 \%$ and the smallest one corresponds to $k_{d}=18 \%$.

\subsubsection{The Dependence of NPV/NOI on Leverage Ratio on Debt $l_{1}$ at Different Values of $k_{d}$}

Let us investigate the dependence of NPV/NOI on leverage ratio on debt $l_{1}$ at $L=1, k_{0}=20 \% ; k_{d}=18 \%$; $\mathrm{t}=20 \%, \mathrm{n}=2$.

We show below the detailed dependence of $\mathrm{NPV} / \mathrm{NOI}$ on leverage ratio on debt $l_{1}$ at $\mathrm{L}=1 ; \mathrm{k}_{0}=20 \%$; $\mathrm{k}_{\mathrm{d}}=14 \%, ! 6 \%, 18 \% ; \mathrm{t}=20 \%, \mathrm{n}=2 ; 5$ ( $i_{1}$ changes from 0 to $3)$.

One can see from Figure 6, that under increase of project duration $\mathrm{n}$ the $\mathrm{NPV} / \mathrm{NOI}\left(\mathrm{I}_{1}\right)$ straight lines shift practically parallel up. The ordering of the NPV/NOI $\left(\mathrm{I}_{1}\right)$ straight lines for different credit rates $k_{d}$ and different project duration $\mathrm{n}$ turns out to be as following: two triplets, corresponding to different project duration $\mathrm{n}$ are well distinguished and upper triplet (with bigger NPV value) corresponds to bigger project duration $n=5$. Within each triplet NPV decreases with credit rates $\mathrm{kd}$ : the biggest NPV corresponds to $k_{d}=14 \%$ and the smallest one corresponds to $k_{d}=18 \%$. It is seen, that influence of the value of credit rates $k_{d}$ increases with $n$, while in case of NPV/D the shift of NPV turns out to be the same for different leverage level $L$.

\section{CONCLUSION}

In this paper we develop for the first time a new approach to ratings of the investment projects of arbitrary duration, applicable to any investment projects and, in particular, to energy projects. The ratings of such energy projects, as "Turkish stream", "Nord stream-2", energy projects relating to clean, renewable and sustainable energy, as well as relating to pricing carbon emissions could be done using developed here new rating methodologies. Paper generalizes the new approach to the ratings of the long-term investment projects, which has been developed in our previous paper (Brusov et al., 2018). The important features of current consideration as well as in previous studies are: 


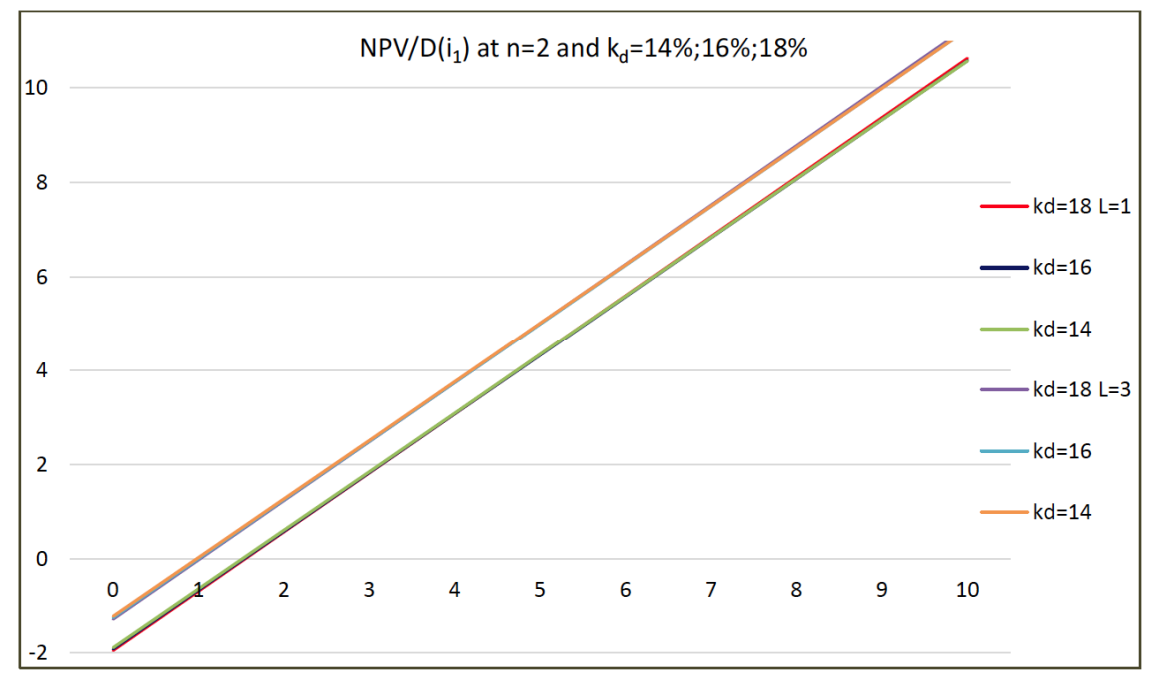

Figure 3: The dependence of NPV/D on coverage ratio on debt $i_{1}$ at $L=1 ; 3, \mathrm{k}_{0}=20 \% ; \mathrm{k}_{\mathrm{d}}=14 \%, ! 6 \%, 18 \% ; \mathrm{t}=20 \%, \mathrm{n}=2\left(i_{1}\right.$ changes from 0 to 10).

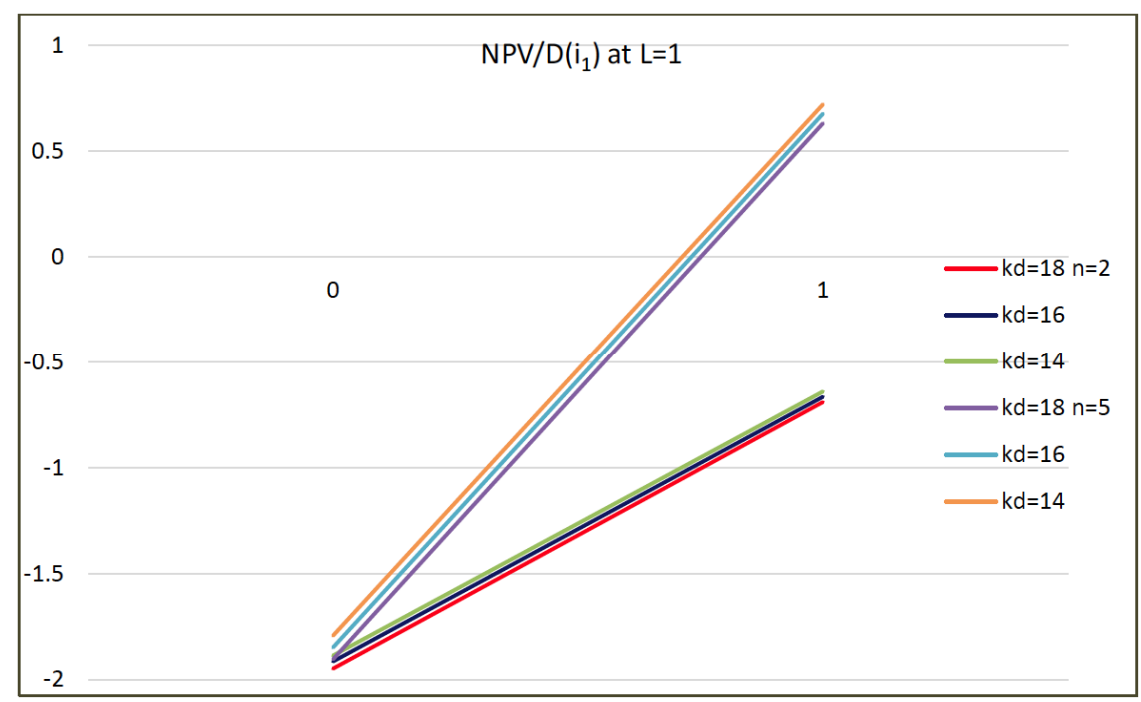

Figure 4: The detailed dependence of NPV/D on coverage ratio on debt $i_{1}$ at $L=1, \mathrm{k}_{0}=20 \% ; \mathrm{k}_{\mathrm{d}}=14 \% ; 16 \% ; 18 \% ; \mathrm{t}=20 \%, \mathrm{n}=2 ; 5$.

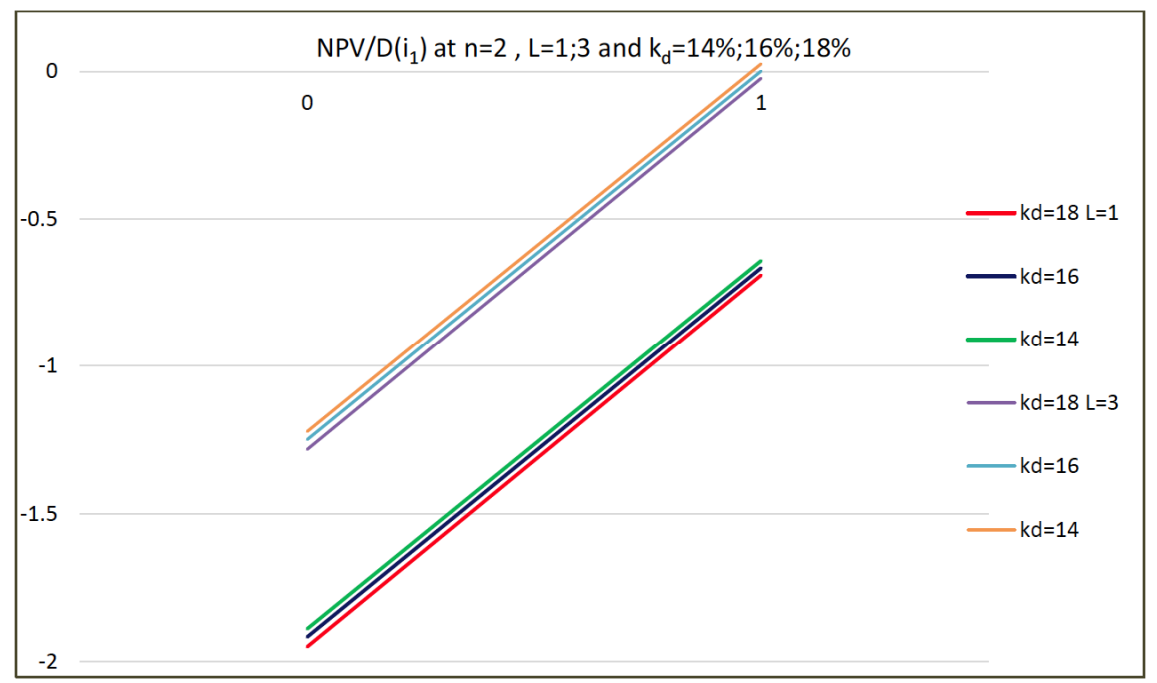

Figure 5: The detailed dependence of NPV/D on coverage ratio on debt $i_{1}$ at $\mathrm{L}=1 ; 3, \mathrm{k}_{0}=20 \% ; \mathrm{k}_{\mathrm{d}}=14 \%, ! 6 \%, 18 \% ; \mathrm{t}=20 \%, \mathrm{n}=2\left(i_{1}\right.$ changes from 0 to 1 ). 


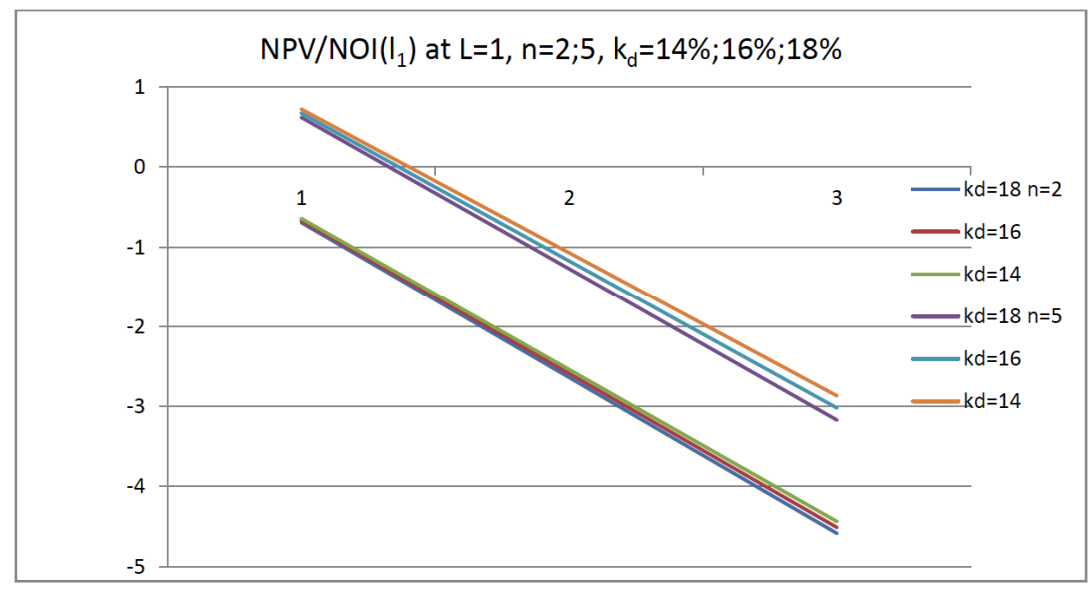

Figure 6: The detailed dependence of NPV/NOI on leverage ratio on debt $l_{1}$ at $L=1 ; \mathrm{k}_{0}=20 \% ; \mathrm{k}_{\mathrm{d}}=14 \%, ! 6 \%, 18 \% ; \mathrm{t}=20 \%, \mathrm{n}=2 ; 5$ (i $i_{1}$ changes from 0 to 3 ).

1) The adequate use of discounting of financial flows virtually not used in existing rating methodologies, 2) The incorporation of rating parameters (financial "ratios"), used in project rating, into considered modern investment models.

We use the modern investment models, created by us, with incorporated financial "ratios" to study the dependence of NPV on rating parameters (financial "ratios") at different values of equity cost $k_{0}$, at different values of credit rates $k_{\mathrm{d}}$ as well as at different values of on leverage level $L$ and project duration $\mathrm{n}$. We study the dependence of NPV on two types of financial "ratios": on the coverage ratios $i_{j}$ as well as on the leverage ratios $l_{j}$. In our calculations we use Excel technique in two aspects: 1) we calculate WACC at different values of equity costs $k_{0}$, different values of debt costs $k_{d}$ and different values of leverage level $L=D / S$, using the famous BFO formula; 2) we calculate the dependences of NPV on coverage ratios as well as leverage ratios at different values of equity costs $k_{0}$, different values of debt costs $k_{d}$ and different values of leverage level $L$.

Analyzing obtained results we have found:

I. NPV (in units of $\mathrm{D})\left(\frac{N P V}{D}\right)$ increases with $\mathrm{i}_{1}$ with following features:

1) the angle $\mathrm{NPV}\left(\mathrm{i}_{1}\right)$ is determined by the project duration $\mathrm{n}$ : it increases with $\mathrm{n}$.

2) with increase of leverage level $L$ the curve $\mathrm{NPV}\left(\mathrm{i}_{1}\right)$ shifts practically parallel up. Thus, NPV increases with debt financing.

This means, that influence of the project duration $n$ on the dependence of NPV/D on coverage ratio on debt $i_{1}$ is more significant, than influence of leverage level $\mathrm{L}$.

II. NPV (in units of NOI) $\left(\frac{N P V}{N O I}\right)$ decreases with $\mathrm{l}_{1}$ with following features:

1) the angle $\operatorname{NPV}\left(I_{1}\right)$ is determined by the leverage level $L$ : it increases with $L$. Thus, NPV increases with debt financing.

2) with increase of project duration $n$ the curve $\mathrm{NPV}\left(\mathrm{I}_{1}\right)$ shifts practically parallel up.

This means, that influence of leverage level $L$ on the dependence of NPV/NOI on leverage ratio on debt $l_{1}$ is more significant, than influence of the project duration n.

One can see that the dependence of NPV/NOI on leverage ratio on debt $l_{1}$ is opposite to the dependence of NPV/D on coverage ratio on debt $i_{1}$ :

1) the angle $\operatorname{NPV}\left(I_{1}\right)$ is determined by the leverage level $L$, while the angle $\operatorname{NPV}\left(i_{1}\right)$ is determined by the project duration $n$.

2) with increase of project duration $n$ the curve $\operatorname{NPV}\left(l_{1}\right)$ shifts practically parallel up, while such kind of behavior is typical for influence of the leverage level $L$ in case of the curve $\operatorname{NPV}\left(i_{1}\right)$.

The only one common thing for both curves $\operatorname{NPV}\left(I_{1}\right)$ and $\mathrm{NPV}\left(\mathrm{i}_{1}\right)$ is that NPV increases with debt financing (or with the leverage level $L$ ). This means that debt financing of the projects of arbitrary duration favors effectiveness of the investment project as well as its creditworthiness. 
The obtained by us results allow make adequate estimation of the effectiveness of the investment projects, NPV, knowing rating parameters (financial "ratios"). For all calculations we use the correct values of discount rate, WACC, which is calculated by use of the modern theory of capital cost and capital structure (BFO theory) (Brusov et al., 2018).

Investigations, conducting in current paper, creates a new approach to rating methodology with respect to the ratings of the investment project of arbitrary duration. It allows use the financial "ratios" for adequate estimation of the effectiveness of the investment projects of arbitrary duration, including energy projects, such as "Turkish stream", "Nord stream-2", etc, energy projects relating to clean, renewable and sustainable energy.

\section{ACKNOWLEDGEMENT}

The reported study was funded by RFBR according to the research project №17-06-00251A/19.

\section{REFERENCES}

Brusov P, Filatova T, Orehova N, Eskindarov M (2015) Modern Corporate Finance, Investments and Taxation, monograph, 368pp., Springer Publishing. https://doi.org/10.1007/978-3-319-14732-1

Brusov P, Filatova T, Orehova N, Eskindarov M (2018) Modern Corporate Finance, Investments, Taxation and Ratings, monograph, 571pp., Springer Nature Publishing. https://doi.org/10.1007/978-3-319-99686-8

Filatova T., Brusov P, Orehova N, Kulk V (2018) Ratings of the longterm projects: New approach. J Rev Global Econ 7:645-661. https://doi.org/10.6000/1929-7092.2018.07.59

Brusov P, Filatova T, Orehova N, Kulk, Weil I (2018a) New Meaningful Effects in Modern Capital Structure Theory. J Rev Global Econ 7:104-122.

https://doi.org/10.6000/1929-7092.2018.07.08

Brusov P, Filatova T, Orehova N, Kulk V (2018b) A "Golden Age" of the Companies: Conditions of Its Existence. J Rev Global Econ 7:88-103. https://doi.org/10.6000/1929-7092.2018.07.07

Brusov P, Filatova T, Orehova N, Kulk V (2018c) Rating Methodology: New Look and New Horizons. J Rev Global Econ 7:63-87. https://doi.org/10.6000/1929-7092.2018.07.06

Brusov P, Filatova T, Orehova N, Kulk V (2018d) Rating: New Approach. J Rev Global Econ 7:37-62. https://doi.org/10.6000/1929-7092.2018.07.05

Brusov P. Filatova T. Orehova N. Brusova A (2011a) Weighted average cost of capital in the theory of Modigliani-Miller. modified for a finite life-time company, Applied Financial Economics 21(11): 815-824. https://doi.org/10.1080/09603107.2010.537635

Brusov P. Filatova P. Orekhova N (2013a) Absence of an Optimal Capital Structure in the Famous Tradeoff Theory! Journal of Reviews on Global Economics 2: 94-116. https://doi.org/10.6000/1929-7092.2013.02.8

Brusov P. Filatova P. Orekhova N (2014a) Mechanism of formation of the company optimal capital structure, different from suggested by trade off theory, Cogent Economics \& Finance 2: 1-13.

https://doi.org/10.1080/23322039.2014.946150

Brusov P. Filatova T. Orehova N et al. (2011b) From ModiglianiMiller to general theory of capital cost and capital structure of the company. Research Journal of Economics. Business and ICT 2: 16-21. https://doi.org/10.1080/09603107.2010.537635

Brusov P. Filatova T. Eskindarov M. Orehova N (2012a) Influence of debt financing on the effectiveness of the finite duration investment project, Applied Financial Economics 22 (13) : 1043-1052. https://doi.org/10.1080/09603107.2011.637893

Brusov P. Filatova T. Orehova $\mathrm{N}$ et al. (2011c) Influence of debt financing on the effectiveness of the investment project within the Modigliani-Miller theory, Research Journal of Economics. Business and ICT (UK) 2: 11-15.

Brusov P. Filatova T. Eskindarov M. Orehova N (2012b) Hidden global causes of the global financial crisis, Journal of Reviews on Global Economics 1: 106-111. https://doi.org/10.6000/1929-7092.2012.01.9

Brusov P. Filatova T. Orekhova N (2013b) Absence of an Optimal Capital Structure in the Famous Tradeoff Theory! Journal of Reviews on Global Economics 2: 94-116. https://doi.org/10.6000/1929-7092.2013.02.8

Brusov P.N.. Filatova T. V. (2011d) From Modigliani-Miller to general theory of capital cost and capital structure of the company, Finance and credit 435: 2-8.

Brusov P. Filatova T. Orekhova N. Brusov P. Brusova A. (2012). Modern approach to dividend policy of company, Finance and credit. v.18. issue 37. 2012.

Brusov P Filatova T Orehova N Brusov P.P Brusova N. (2011e) From Modigliani-Miller to general theory of capital cost and capital structure of the company, Research Journal of Economics. Business and ICT 2: 16-21. https://doi.org/10.1080/09603107.2010.537635

Brusov P Filatova T Orehova N (2014b) Inflation in Brusov-FilatovaOrekhova Theory and in its Perpetuity Limit - Modigliani Miller Theory, Journal of Reviews on Global Economics 3: 175-185. https://doi.org/10.6000/1929-7092.2014.03.13

Brusov P Filatova T Orehova N (2013c) A Qualitatively New Effect in Corporative Finance: Abnormal Dependence of Cost of Equity of Company on Leverage, Journal of Reviews on Global Economics 2: 183-193. https://doi.org/10.6000/1929-7092.2013.02.15

Brusova A (2011) A Comparison of the three methods of estimation of weighted average cost of capital and equity cost of company. Financial analysis: problems and solutions 34 (76): 36-42.

Filatova T Orehova N Brusova A (2008) Weighted average cost of capital in the theory of Modigliani-Miller, modified for a finite life-time company, Bulletin of the FU 48: 68-77.

M. McAleer, C.-L. Chang and Y. Wang (2018a ) "Testing co-volatility spillovers for natural gas spot, futures and ETF spot using dynamic conditional covariances", Energy, 151, 984-997. https://doi.org/10.1016/j.energy.2018.01.017

M. McAleer, C.-L. Chang and Y.-Y. Li (2018b ) "Volatility spillovers between energy and agricultural markets: A critical appraisal of theory and practice", Energies, 11(6:1595), 1-19. https://doi.org/10.3390/en11061595

M. McAleer, C.-L. Chang, J. Ilomäki and H. Laurila (2018c ) "Moving average market timing in European energy markets: Production versus emissions", Energies, 11(12:3281), 1-24. https://doi.org/10.3390/en11123281

M. McAleer, C.-L. Chang and T.-K. Mai (2019) "Establishing national carbon emission prices for China", Renewable and Sustainable Energy Reviews, 106, 1-16. https://doi.org/10.1016/j.rser.2019.01.063 
Modigliani F. Miller M (1958) The Cost of Capital, Corporate Finance and the Theory of Investment, American Economic Review 48: 261-297

Modigliani F. Miller M (1963) Corporate Income Taxes and the Cost of Capital: A Correction, American Economic Review 53: 147-175

Received on 11-06-2019
Modigliani F. Miller M (1966) Some estimates of the Cost of Capital to the Electric Utility Industry 1954-1957, American Economic Review 56: 333-391

DOI: https://doi.org/10.6000/1929-7092.2019.08.37

(C) 2019 Brusov et al.; Licensee Lifescience Global.

This is an open access article licensed under the terms of the Creative Commons Attribution Non-Commercial License (http://creativecommons.org/licenses/by-nc/3.0/) which permits unrestricted, non-commercial use, distribution and reproduction in any medium, provided the work is properly cited. 